Yoanna Skrobik

\title{
Praying for healthy minds and healthy bodies in ICU survivors
}

Received: 1 June 2010

Accepted: 3 June 2010

Published online: 27 July 2010

(C) Copyright jointly held by Springer and ESICM 2010

Y. Skrobik ( $)$

Hopital Maisonneuve Rosemont-Critical Care,

5415 Boul. De l'Assomption, Montreal,

QC H1T 2M4, Canada

e-mail: skrobik@sympatico.ca

Tel.: +1-514-2523400

Fax: +1-514-9398891

Advances in intensive care practice and technology allow severely ill patients to survive conditions that would have been fatal 50 years ago; however, survival of critical illness is often associated with psychiatric sequelae, and this is just beginning to be understood. In a study in this issue of Intensive Care Medicine, Amal Jubran and colleagues [1] describe the prevalence of post-traumatic stress disorder (PTSD) in patients in a weaning unit. PTSD is an important problem. It is associated with poor quality of life and an increased risk of suicide, but it is amenable to intervention, particularly if it is implemented early. This study, conducted in patients well enough and lucid enough to be interviewed, suggests that PTSD is common both in the weaning unit and after discharge. In contrast to earlier questionnaire-based studies, patients included in this study were rigorously assessed by the gold standard, an interview by an experienced clinician. A simple questionnaire, however, was a good predictor of PSTD. The questionnaire validation was important because the cutoff score for the correlation between a clinical diagnosis and a predictive score was much lower than is described with this PTSS-10 PSTD instrument in the
ARDS (acute respiratory distress syndrome) critically ill population. The occurrence of PSTD was not associated with severity of illness or duration of weaning, but it was associated with a previous psychiatric diagnosis. The study is therefore relevant to the clinical intensive care practitioner, has implications that patients are likely to care about, and it proposes actionable results.

The burden of psychiatric symptoms among the critically ill is considerable, at least in the acute phase of illness. Clinical depression has been described by the same authors in over $40 \%$ of weaning unit patients [2]. Cognitive abnormalities suggesting delirium or subsyndromal delirium [3] occur in $70-80 \%$ of ICU patients. Despite the aging population, more patients survive critical illness, but they often emerge from intensive care with myopathy, in addition to suffering from ailments ranging from PTSD to perceptual disturbances.

A few ICU studies suggest cause for cautious optimism in the ability to influence outcomes in these psychiatric disturbances. Early and aggressive mobilization is associated with less overall delirium, earlier home discharge, and lower hospitalization costs. Merely warning patients that they may develop delirium following cardiac surgery does not lower the rate of delirium, but decreases the administration of sedation and lessens the fear experienced by patients [4]. Adjusting analgesics, sedatives, and antipsychotics to specific individual patient symptoms appears to be associated with less subsyndromal delirium and a higher probability of returning home [5]. Sedation with dexmedetomidine, a central alpha blocker, is linked with less frequent delirium than sedation with midazolam [6]. Giving patients quetiapine once ICU delirium is established may help [7] reduce delirium duration. Lessening depression or PTSD symptoms, however, has not been described. Nothing is understood of causality. The authors raise the spectre of the vulnerability vis-à-vis PTSD brought on by a prior psychiatric diagnosis, but whether variability in neurotransmitters, exposure to 
short- or long-term psychotropic drugs, or the impact inflammatory mediators have on brain function are involved in PTSD or in other psychiatric disorders is completely unclear.

Some of the difficulties intensivists face may have to do with the variability in diagnosing psychiatric disorders in mechanically ventilated or otherwise uncommunicative patients [8]. Even in verbal patients there is no troponin equivalent for PTSD. Jubran et al. suggest that an exit questionnaire, taken a week after weaning, may triage atrisk patients. Unfamiliarity and discomfort is another dimension to psychiatric disease such as PTSD; soldiers returning from wars are witnesses to it. Despite decades of neuropsychiatric research, there is little mechanistic insight into psychiatric disease, while much emphasis is placed on pharmacologic control of symptoms. Some of the challenge may have to do with how far the intensivist, focused on physiology and technology rather than patient perceptions, is removed from psychiatry as a specialty. Finally, the 'right' approach to prevention and treatment for the psychiatric symptoms in this population is unknown.

Juvenal entreated Romans to only pray for physical and mental health ('mens sana in corpore sano'). A patient in a critical care unit might pray for the same. It is heartening that two authors who taught us so much about respiratory physiology now invite us to consider a more holistic patient care perspective.

\section{References}

1. Jubran A, Lawm G, Duffner LA, Collins EG, Lanuza DM, Hoffman LA, Tobin MJ (2010) Post-traumatic distress syndrome after weaning from mechanical ventilation. Intensive Care Med. doi:10.1007/s00134-010-1972-8

2. Jubran A, Lawm G, Kelly J, Duffner LA, Gungor G, Collins EG, Lanuza DM, Hoffman LA, Tobin MJ (2010) Depressive disorders during weaning from prolonged mechanical ventilation. Intensive Care Med 36:828-835

3. Ouimet S, Riker R, Bergeron N, Cossette M, Kavanagh B, Skrobik Y (2007) Subsyndromal delirium in the ICU: evidence for a disease spectrum. Intensive Care Med 33:1007-1013
4. Owens JF, Hutelmyer CM (1982) The effect of preoperative intervention on delirium in cardiac surgical patients. Nurs Res 31:60-62

5. Skrobik Y, Ahern S, Leblanc M, Marquis F, Awissi DK, Kavanagh BP (2010) Protocolized intensive care unit management of analgesia, sedation, and delirium improves analgesia and subsyndromal delirium rates. Anesth Analg [Epub ahead of print]

6. Riker RR, Shehabi Y, Bokesch PM, Ceraso D, Wisemandle W, Koura F, Whitten P, Margolis BD, Byrne DW, Ely EW, Rocha MG (2009) Dexmedetomidine vs midazolam for sedation of critically ill patients: a randomized trial. JAMA 301:489-499
7. Devlin JW, Roberts RJ, Fong JJ, Skrobik Y, Riker RR, Hill NS, Robbins T, Garpestad E (2010) Efficacy and safety of quetiapine in critically ill patients with delirium: a prospective, multicenter, randomized, double-blind, placebocontrolled pilot study. Crit Care Med 38:419-427

8. Cheung CZ, Alibhai SM, Robinson M, Tomlinson G, Chittock D, Drover J, Skrobik Y (2008) Recognition and labeling of delirium symptoms by intensivists: does it matter? Intensive Care Med 34:437-446 